DOI: $10.21625 /$ resourceedings.v1i1.181

\title{
INFORMAL ECOLOGY: AN EMERGENT APPROACH TOWARDS LANDSCAPE INTEGRATION IN CARACAS, VENEZUELA
}

\author{
Natacha Quintero ${ }^{1}$ \\ ${ }^{1}$ Technische Universität Berlin Campus El Gouna, Berlin, Germany
}

\begin{abstract}
Keywords
Urban ecology, urban informality, Caracas, systems thinking, integrated landscapes;
\end{abstract}

\begin{abstract}
Intended as a contribution to the debate on inclusive cities, this paper proposes that the re-imagination of new city landscapes lies on the integrative sum of its parts. Considering that knowledge about informal systems continues to be a challenge in achieving integrated landscapes, this study explores how the linking of the fields of urban ecology and urban informality can lead to systematic approaches towards understanding urban informal ecosystems. In that way, this think- piece theorizes on alternatives to approach the socio-natural processes taking place in informal settlements to demonstrate their capacity to adapt to prescribed ecological frameworks and ease their way into ecological scrutiny. Using a mixed-method approach in which theoretical framework and the empirical work functioned in a cyclical manner, the city of Caracas, Venezuela, was investigated. The analysis led to the discovery of ties and processes that navigate in and out of the informal city and revealed that informal areas can be scaled, inventoried, and re-imagined from a systems perspective. The paper, therefore, recommends a rethinking of the two intersections that play a role in most of the new scenarios of change seen in the contemporary urban hybrids of developing countries. Specifically, the intersection that concerns the formal vs informal dichotomy, exploring the spatial and virtual role of the urban informal in the city, and the one concerning the city vs nature dichotomy, and the assumption that as part of the city, the informal is also a constituent of a greater urban ecosystem with impacts and evolutionary capacities.
\end{abstract}

\section{Introduction}

The magnitude of urbanization along with the extensive decay of natural systems have led cities to recognize the importance of approaching these two colossal scenarios of change in an integrated way. This recognition, advocated by both international development agencies and local administrations, pushes forward theoretical and practical explorations towards planning approaches focussed on anticipation, mitigation, and adaptation to change. In the same way, the acknowledgment of a challenging exacerbation of urban poverty has prompted further explorations in improving living conditions in informal settlements, strategies for poverty alleviation, and urban upgrading. What remains less explored, however, is how integrated planning and sustainable development considers the informal as an active constituent in the ecological discourse and how informal settlements can engage in the transformative processes that make new urban scenarios.

Based on an exploratory study, this paper aims to introduce to the notion of 'informal ecology' as an integrative approach that encourages improved visualization of socio-natural processes taking place in- formal areas. It intends to do so by analyzing the potential of systems ecology for adapting to urban informal development in the envisioning of new city landscapes. Within the exploration of the 'formal vs informal' dichotomy and the role of the informal in the imagination of new landscapes, this paper also concerns the 'city vs nature' dichotomy with the aim of rendering 
the informal as a significant constituent of the greater urban ecosystem of the city. Purposely, this paper concentrates on the contemporary urban landscapes that the Latin American region is displaying after having faced a rapid urbanization process from the sixties to the eighties. More specifically, the case of Caracas is investigated as an archetype capital city marked by a consolidated urban informal landscape and a challenging slum development.

Main findings indicate the role of data in the reappraisal of systems ecology as an alternative for socio-natural integration of informal settlements in the urban landscape. Hence, it is also aimed at shedding light on the issue of collecting and interpreting data from informal settlements, underlining the need for alternatives to further exchanges between informal areas and the totality of the city, to acknowledge their constant state of transformation, and rethink their significance in the city landscape. Limited data, as well as the intrinsic issues of researching in informal areas, make this research a contribution towards encouraging the conversation about the ecology in informal areas.

The first part of this paper provides the theoretical framework that allows for the fields of urban ecology and urban informality to converge. The second part briefly describes the Caracas context and gives an outline of the research methodology chosen for the study. The third section analyses the capacity of systems ecology to adapt to urban informal development. In a final section, findings and the prospects for informal ecology are discussed.

\subsection{Informal Urbanisation and Ecological Theory}

Most cities in the world are facing the coexistence of several forms of urbanization. The simultaneous collapse of these forms into one manifestation, which in Latin America, Asia, and Africa takes on "a bizarre form", reverse the city's physical form and generate a specific set of urban conditions that result in the placement of the "static", or formal city, within the temporal landscape of the "kinetic", or informal city (Hernández et al., 2012, sec. Foreword). Informality, firmly identified as a substantial issue faced by cities and urban dwellers, and one of the greatest challenges for contemporary and long-established research (Porter et al., 2011) has seen a burgeoning interest driven by both, unsatisfying empirical and theoretical work in the past, and novel explorations, of conceptual and analytical nature, on urban spaces diversely influenced by global flows (Parthasarathy, 2009).

Informal housing and informal labor have gained recognition as significant constituents of urban economies. Addressing informality as "mode rather than a sector" allows for the inclusion of further understandings, initiates a discussion over crucial new urbanisation trends, and highlights the urgency to better-learn from cities of the Third World so as to avoid the replication and borrowing of planning practices, as well as to go beyond a dichotomy that uses "First World models" to address "Third World problems" (Roy, 2005, p. 147,148). Contrary to frameworks conceptualizing the 'informal' as equivalent to poverty or marginality, there is an opportunity to understand informality as "an idiom of urbanization" not restricted to the limitations of the slum but rather seen as a connecting mode of space production (Roy, 2011, p. 233). Hence, when informality is accepted not as a mode "outside" of formal systems, but as "produced by formal structures", the analytical and conceptual re-connection of the informal with the formal becomes then a transaction between both modes (Porter et al., 2011, p. 116).

Lessons learned and continuous critical reflections have started a powerful paradigm shift that addresses informality as a contemporary and unique mode of urbanization (Roy, 2005). This shift encourages the recognition of the urban informal dweller not only as a partaker in a set of exchanges occurring within and out of the informal realm but as a constituent of a greater system. However, as much as informality has promisingly progressed in research as a dynamic force (McGuirk,2014) that far from chaotic is considered 'kinetic' and passing local knowledge into the contemporary realm - with flow, instability, and indeterminacy as basic features (Hernández et al., 2012, sec. Foreword, xii), urban informal dwellers still bear the social disparities, segregation, precarious employment conditions, and spatial disadvantages related to informality. The urban poor is also particularly at risk and vulnerable when it comes to impacts of environmental degradation (Garland et al., 2007). Although poorest nations are not considered the main cause of major environmental impacts (United Nations, 2016, sec. Population), expected population growth will mostly

happen in urban slums lacking planning and services in geographies that are least equipped to handle extra demands (Garland et al., 2007, p. 1). Moreover, in an era of rapid urbanization in the developing world, research on socioecological theory has concentrated in cases from developed countries of the so-called 'Global North' (McHale, Bunn, et al., 2013).

Heynen, et al. (2006) made observations on how surprising it is, that is growing literature on environmental sustainability and environmental politics, the attention on urban environments is neglected or replaced by issues with a markedly global tone such as climate change, desertification, deforestation and so on. In the same way, a bulk of literature on urban studies regrettably omits the physical-en- environmental grounds where urbanization happens. Indeed, efforts to integrate social and natural sciences keep treating human and ecological processes as isolated from each other (Heynen et al., 2006) and still, humans remain excluded from much of the ecological scrutiny despite the fact that they are now known to dominate all of the Earth's ecosystems (Alberti et al., 2003). 
The way humans and natural systems co-exist is gaining attention from ecological scholars, especially when studying urban regions (Al- Berti, 2005). It has been argued that urbanization is a process whereby the natural environment, is substituted for or rather appropriated by, an unpleasant "built" environment. More structured views suggest, however, that cities are produced environments resulting from historical outcomes of a set of socio-environmental processes. Specifically, "cities are built out of natural resources, through socially mediated natural processes" (Heynen et al., 2006, p. 4), and an opportunity to rethink how cities find their place in the material world seems to show promise if appreciated through the ecological lens, especially through urban ecology (Melosi, 2010). The extents and magnitude of urban areas and their populations are enough reasons to become subjects of study, however, ecologists should establish effective relations with decision makers in the field of regional planning and conservation if they want to ensure proper management of cities as adequate places to live in the future (Pickett et al., 2001).

\subsection{Cities, Nature and Frameworks to approach Urban Ecosystems}

Cities are defined as "dense networks of interwoven socio-spatial processes that are simultaneously local and global, human and physical, cultural and organic". These connected processes combine countless transformations and metabolisms supporting and maintaining urban life in them (Heynen et al., 2006, p. 1,2). Cities are now being studied as "emergent phenomena", and are considered "complex ecological entities" - each with their own distinctive rules of growth, behavior, and evolution" (Alberti et al., 2003, p. 1170). According to Alberti et al. (2003), a city is comparable to any other ecosystem in that populations have both properties and behaviors not inherent to individuals. Each constituent of the city contributes to, yet has no control over, the form and behavior of the whole. What differs urban areas from any other ecosystem is the role of humans as dominant components. Urban ecosystems also differ from other human-dominated ecosystems in terms of growth, the range of influence, and impacts (McIntyre et al., 2000). Urban ecosystems, filled with people and their activities, are energy-intensive, and in conventional ecological terms, the most unbalanced in comparison with other ecosystems (Collins et al., 2000).

When studying urban ecosystems, Endlicher et al. (2007, p. 5), argue that scale plays an important role. Specifically, three scales are to be distinguished especially in larger cities: the micro-scale, referring to the neighborhood and its specific built-up features; the mesoscale, referring to the district and the mixture of different sets of land use types; and the macro-scale, which concerns to the entire urban area. This categorization is particularly useful for generalization when certain prototypes of a "virtual city" are identified through typical neighborhoods, districts or cities. Besides the spatial dimension, urban ecology also concentrates on processes of change in space and time. Endlicher et al. (2007) indicate four main processes of change as key to understanding how natural and social spheres interact: 1) changes in urban biodiversity, 2) climate change, 3) demographic change, and 4) economic change. Within these main processes, two research clusters may be identified, the natural sphere or natural system of a city (abiotic and biotic spheres), and the anthroposphere, or socioeconomic system of a city (society and economy).

Cities have been described by economists, urban planners, and sociologists as "self-organizing systems" in which distinct neighborhoods and unplanned socioeconomic, physical, and demographic clusters are created by bottom-up processes (Alberti et al., 2003, p.1174). As unique as they are, cities resemble one another in pattern and function. The repetition of their location types and their internal structure occurs so often that it allows for wide and suggestive generalizations (Harris \& Ullman, 1945). As discussed by Harris and Ullman (1945), two basic features in the nature of cities are their 'support' and their 'internal structure'. The support of cities refers to the services a city performs not just for itself but for a whole fiscal area, meaning the chain of interconnected activities by which a city can earn its livelihood. Accordingly, and not meant as a fixed framework, urban occurrence in the support of cities can be reviewed in three categories: (a) Cities as central places carrying out wide-ranging services for an adjoining area, (b) Transport cities performing transferring, distribution and associated services along transport routes, and (c) Specialised-function cities carrying out one specific service related to a specific resource, often occurring individually or in clusters. Harris \& Ullman (1945, p. 12) further argue that even unexpected development of any kind comes to be part of the general "urban-sup- porting environment". In that sense, they suggest that the urban setting should not be considered static and that cities are in constant change and go through intervals when adjusting to new conditions. The processes of change can result from alterations in the 'internal structure of cities' and consequently, any potential arrangements must consider current patterns of land use, the causal condition of those patterns and the particular activities located in each area.

Collins et al. (2000), also draw attention to the dynamicity and the constant change to which the urban ecosystem is always subjected. It is noted that the forces driving change in urban ecosystems are similar to those found in nonurban systems, as in the case of disturbances. An example can be the incidence of fires, earthquakes, and flooding; all disturbances that are bound to happen in cities, even if people are in the constant struggle when trying to control their magnitude and the frequency. The ability of a system to absorb an amount of disturbance and still remain within the same realm of attraction, as well as its adaptive capacity when facing small, continuous or sudden change is defined as resilience (Pickett et al., 2011). An ecosystem is an unpredictable and uncontrollable moving force in constant 
evolution at multiple temporal and spatial scales (Abel, 1998). The study of systems dynamics has been found in literature as a useful approach for increasing knowledge in properties and cycles in systems. A powerful and resourceful representation of systems dynamics is the lazy-eight adaptive cycle model by ecologist Crawford Stanley Holling (1986) (as reviewed by Fath et al., 2015). The model, known as the Holling's model includes a total of four stages, respectively: growth $(\mathrm{r})$, equilibrium $(\mathrm{K})$, collapse $(\Omega)$, and reorientation $(\alpha)$, and has been subject of revision modifications for expansions in the study of resilience (See modification by Burkhard et al., 2011) (Appendix 1). The adaptive cycle has been used as a holistic approach to identify dominant properties in systems as well as systematic pathologies resulting from traps in the cycles (Fath et al., 2015). In addition, it is desirable for the understanding of systems behavior time-extended databases of socio-ecological systems able to facilitate answers to pragmatic questions regarding greater settings. Knowing the place of the system in the adaptive cycle can lead to knowing its resilience, however, long-term records allow critical reappraisal of the circumstances under which the dynamics identified through such conceptual models are seen or left unseen (Dearing et al., 2012).

Further understandings on how to assess urban systems contemplate the specific socio-environmental conditions of specific areas through integrated frameworks and models. Ecosystems consist of habitats of "patches", and the city is considered a "patchy ecosystem", in which processes, distribution of resources, and interactions vary (Collins et al., 2000, p. 419). Representative frameworks such as the Human Ecosystem Framework (Appendix 2) have emerged from the social sciences in order to study interactions between people and their environment. This analytical framework identifies physical and social variables and interactions including some less common features in ecological analysis such as cultural resources, myths, or justice (Pickett et al., 2011). The significance of social and biophysical drivers can vary over time, and every component in the framework is subjected to constant assessment in relation to other components. In addition, the framework can be operationalized depending on two elements, a causal framework, and a template that analyses how causes and features interact to create other urban complexes. Feedback is an important aspect of both frameworks and template. Finally, these are followed by an operational model (Pickett et al., 2011). In earlier work, Pickett et al. (2001) presented a human ecosystem framework which indicated the most basic components of any ecosystem affected or influenced by humans. This framework (Appendix 3) integrates biogeophysical and social structures within more general phenomena as well as an integration in which social systems interact with resource systems. According to Alberti et al. (2003), these models fail to represent dynamic interactions between human and biophysical components, processes, and patterns, or their feedbacks. Instead, they proposed an integrated model (Appendix 4) in which biophysical and human agents can interchangeably assume the function of drivers, effects, patterns, and processes. The utility of this model is that ecological scholars using it can raise questions about the way in which patterns of human and ecological responses appear from interactions between human and biophysical processes, as well as how such patterns impact resilience in urban ecosystems (Alberti et al., 2003, p. 1174).

\section{Case study, data, and methods}

\subsection{Caracas Context}

Within the context of the Latin American region, Caracas, capital of Venezuela, has been chosen for this study. Apart from its tropical climate and its richness in oil, Caracas is also known for its challenging barrio ${ }^{1}$ development. Concentrating all the country's manifestations in one city, Caracas represents an ever-changing landscape and a dynamic mixture of urbanizing forms. This contemporary hybrid is characterised by a "turbulent" political and social history (Hernández et al., 2012, p. 57) - contemporarily epitomised by the shifting policies initiated by President Hugo Chavez (See Ayala, 2009; Harrison-Con- will, 2011); an early and explosive urbanisation process, and current tactical efforts influencing the way urban upgrade materialises.

The city is located in a $30 \mathrm{~km}$ wide valley adjacent to the Caribbean Sea. Its establishment responded to the advantages of fertile soils, suitable grounds for construction works, the affluence of water resources (De Lisio, 2001), and tropical climate. Featuring the prominent Avila Mountain as a natural urban border, the city also benefits from its role as a natural ventilator and refresher to the center and the northern areas (Córdova Sáez, 2011; Córdova Sáez \& Singer, 2010). Caracas is also distinctly marked by the Guaire River, which centrally defines the city from east to west. With a complex topography and geology, part of which relates to the complex fault zones Avila Mountain presents (Dengo, 1953), Caracas is also prone to landslides and at constant risk of flooding. Although these hazards were typically associated with the seismic activity and natural precipitation cycles during the $60 \mathrm{~s}$ and the $70 \mathrm{~s}$, their incidence is rather attributed to the disregard to the terrain's instability during urbanization processes, especially those of informal urbanization (Diaz, 1992). High densities of people living on hillsides continue to pose great occupational risks and

\footnotetext{
${ }^{1}$ Barrio: Term used in Venezuela to denominate informal settlements and slum areas.
} 
high pressures on soil and water resources. Changes in temperature also represent a challenge for the city. Studies have shown increased temperatures and climate events with particular intensity in areas with high traffic and vehicular corridors, in the northern parts of the city, and especially in the Libertador Municipality, which concentrates more than half of the population of the city (67\%) and the lowest income groups (Córdova Sáez, 2011; Córdova Sáez \& Singer, 2010).

Estimates from 2015 reported that $11.95 \%$ of the country's urban population lived in Caracas. With an estimated national slum population of 7.90 million, 7.86 million of which is urban (United Nations Human Settlements Programme, 2016), an approximate of 2 million dwell in Caracas (Cilento, 2012). Other sources show more dramatic figures, according to Sertich (2010), out of 4.7 million inhabitants, 3.2 million live in informal settlements, meaning approximately $60 \%$ of the population or two-thirds of the population. Although figures vary, slum population represent in all cases more than $45 \%$ of the urban population. Much of the low-income population occupies the south-west and western areas of Caracas, areas which have been recognized as having most of the socio-environmental issues (Córdova Sáez, 2009), except for Petare, the city’s largest slum located at the north-east of Caracas (Caselli, 2013).

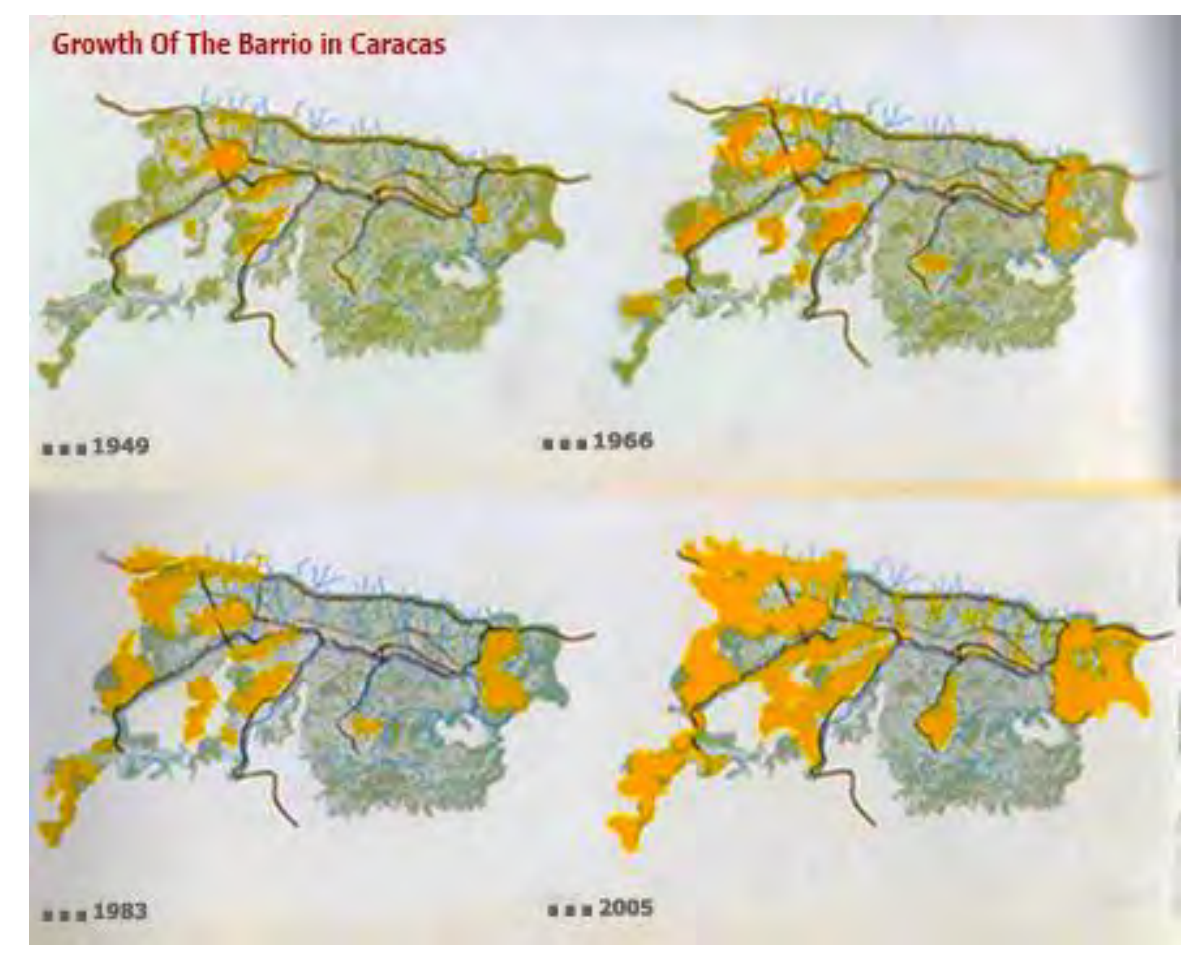

Figure 1. The growth of the barrio in Caracas, 1949, 1966, 1983, 2005. Reprinted from the Informal city: Caracas case (p. 216, 217). Caracas U-TT, A. Brillem- Bourg, K. Feireiss, and H. Klumpner, (2005). Munich ; New York: Prestel: Kulturstiftung des Bundes (Eds.).

Although slum dwellers are subjected to environmental issues, poverty, illegality, lack of tenure, and lack of institutional buildings and public spaces; their ability to produce real estates, which visibly sur- passes the capacities of the public and private sector by two and even three times (Bolívar \& Baldó, 1996), to transform housing units or ranchos ${ }^{2}$, from shacks made out of waste or non-durable materials to consolidated houses (Diaz, 1992), and to show entrepreneurial skills, drive, and inventiveness in commercial doings, have all contributed to a shift in the way practitioners approach barrios. Continuously rejecting simplistic and negative views of barrios as spaces for chaos, incompetence, crime and misery, barrios are now seen as self-regulatory entities and as heterogeneous places, with positive features and potentials for extension, development, and reproduction (Caracas Urban Think Tank et al., 2005, p. 217).

In Caracas, the co-dependencies between formal and informal are palpable (Caracas Urban Think Tank et al., 2005), and the patterns of self-organization observed in barrios provide an insight to their housing techniques, informal economic activities, and different layers of the social organization. These different and transforming forms of occupation are in a certain way, a manifestation of a kind of resilience and creative adaptation (Wright, 2005). Urban informal dwellers show resilience because of their capacity to endure fears, risks, and uncertainty, as much as for

\footnotetext{
${ }^{2}$ Rancho: Improvised housing unit, usually made of precarious materials such as cardboard, and untreated wood or metal recycled panels.
} 
showing high knowledge of their environment, and practicing solidarity and cooperation, even if such efforts are bounded to traditions and informal understandings (Cilento, 2012).

\subsection{Methodological Strategy}

This paper explores the potential of systems ecology for adapting to urban informal development in the envisioning of new city landscapes. In doing so, a mixed-method approach in which the theoretical framework and the empirical work functioned in a cyclical manner was adopted. This methodology enabled a new theoretical background to explore the potentials of applying integrative ecological frameworks to specific urban informal areas, while the results of empirical data collection processes served as feedback in its restructuration (Fig. 2).

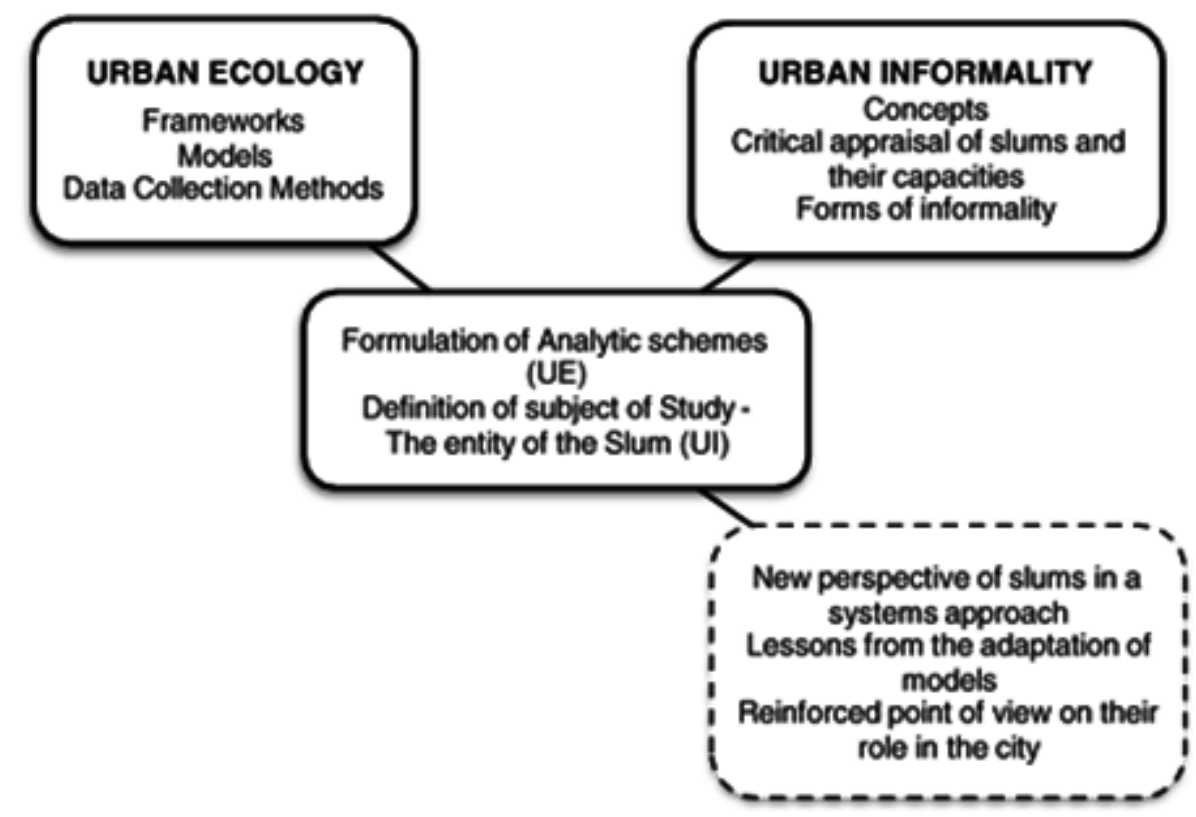

Figure 2. Methodological strategy for linking the two fields of urban ecology and urban informality and developing the initial conceptual background.

A case study design was chosen due to its strength in addressing contemporary phenomena and situations in which there is little control over events (Yin, 1994), also, for its ability to add focus to the contextual analysis of specific events (Dooley, 2002). The selection of specific topics was influenced by inputs from the data collection process and defined after a process of matching and re-shaping with the initial background. This process reflected the cyclical manner of the methodology and the philosophy of going back and forth between empirical and theoretical frameworks, a theory-development method based on the systems combining approach identified by Dubois \& Gadde (2002, 2014). The criteria for selecting the specific study cases within the city followed specific variables including the scope of the study, the correspondence to research categories defined after a document analysis, the availability of data, and the results from empirical work.

The data collection process for this qualitative study was carried out using three methods: a qualitative analysis of secondary data, questionnaires, and individual open-ended, semi-structured interviews with experts. Secondary analysis of existing qualitative research data was used as a resourceful method for bringing new perspectives to existing data, making use of under-analyzed elements of the data, and setting foundations for comparing original data with new one, as indicated by Ritchie \& Lewis (2003). The qualitative analysis of secondary data was carried out giving special attention to four parent categories and a discarding criterion. Within the initial categories were documents related to slum upgrade, natural features and events, social and institutional development, and policymaking. The time framework for the systematic analysis of archival data and documents was established from the end of the decade of 1970's to the present day. This decision considered the shift in perspective from forced eviction and reallocation to in-situ upgrade and comprehensive plans; and the aim of the study to analyze a case study that reflects contemporary phenomena. The type of documents included reports on slum upgrading projects with extensive site analyses, the literature on policy formulation and development plans, texts on critical analysis of current plans and practices, maps, and descriptive studies on biophysical characteristics of the city.

Semi-structure questionnaires were administered to a sample group of twenty experts from which ten, representing academia, architectural and planning studios, urban upgrading initiatives, and engineering, were successfully processed. A total of 26 projects in informal areas of Caracas were registered from which $60 \%$ were in progress, $20 \%$ 
to be executed and 20\% completed (Fig. 3). Experts were identified through electronic sources, institutional websites, network-based contacts, and recent literature on upgrading projects in Caracas. Yin (1994) suggests that relevant field contacts rely on the comprehension of the theoretical background of the subject of study. In that sense, the literature considerably revealed the sample group to analyze. This sample was determined based on their theoretical and practical knowledge about the matter under investigation.

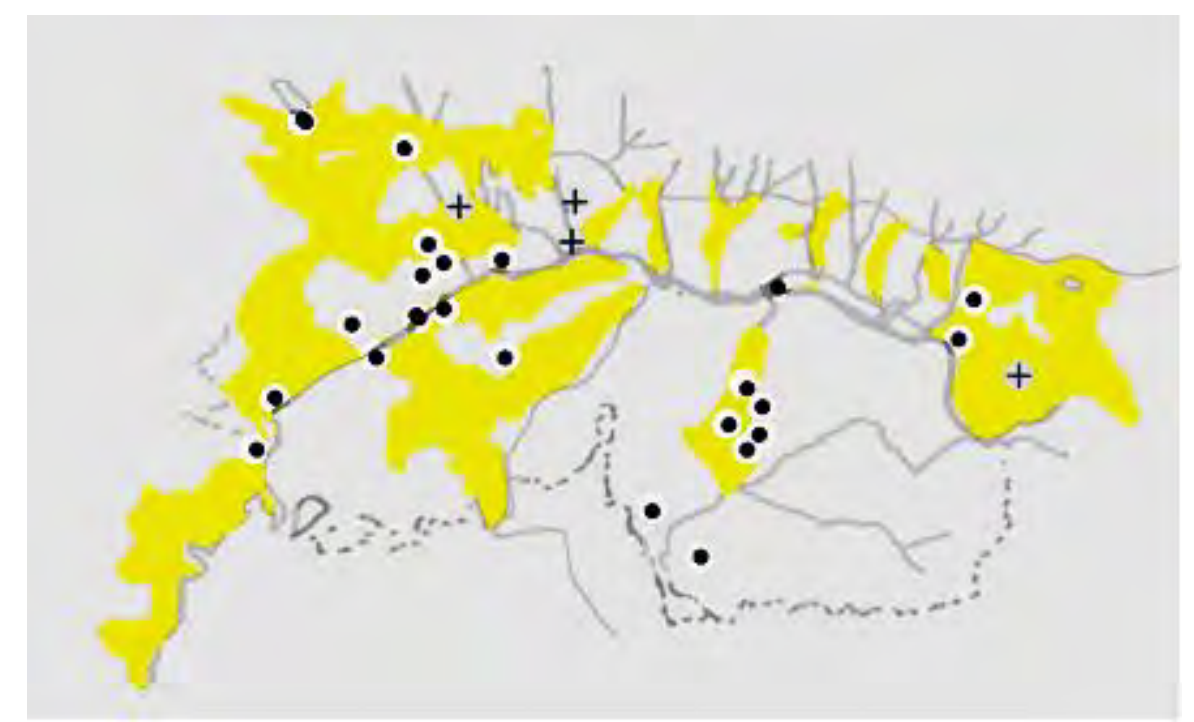

Figure 3. Map of upgrading projects in Barrios of Caracas surveyed during the data collection process. Crosses represent projects executed before 2000; dots represent those executed after 2000. Own elaboration.

Once questionnaires were analyzed, the respondents were asked to participate in individual interviews to extend their responses to the questionnaires. Seven out of ten experts were interviewed through semi-structured interviews. Although the variety of disciplines aimed at in the original sample was not achieved during the research period, architects and planners interviewed showed extensive knowledge in slum development as well as in other disciplines related to upgrading in informal areas, such as engineering and construction works, environmental design, and sociology. Interviews provided detailed accounts of development projects and processes within slums that were not found in literature, thus, becoming highly influential in the research process. Correspondingly, some concepts that surfaced during interviews were used to refine the codes for analysis of data. Responses from questionnaires and interviews were systematically analyzed following a number of codes. Specific codes, i.e. processes, actors, drivers, components, disturbances, emergent features, tools, connectors, and bridges; were defined by associating the main categories of analysis to the theoretical framework. 


\section{Re-thinking the urban informal ecosystem in Caracas - Exploration, and findings}

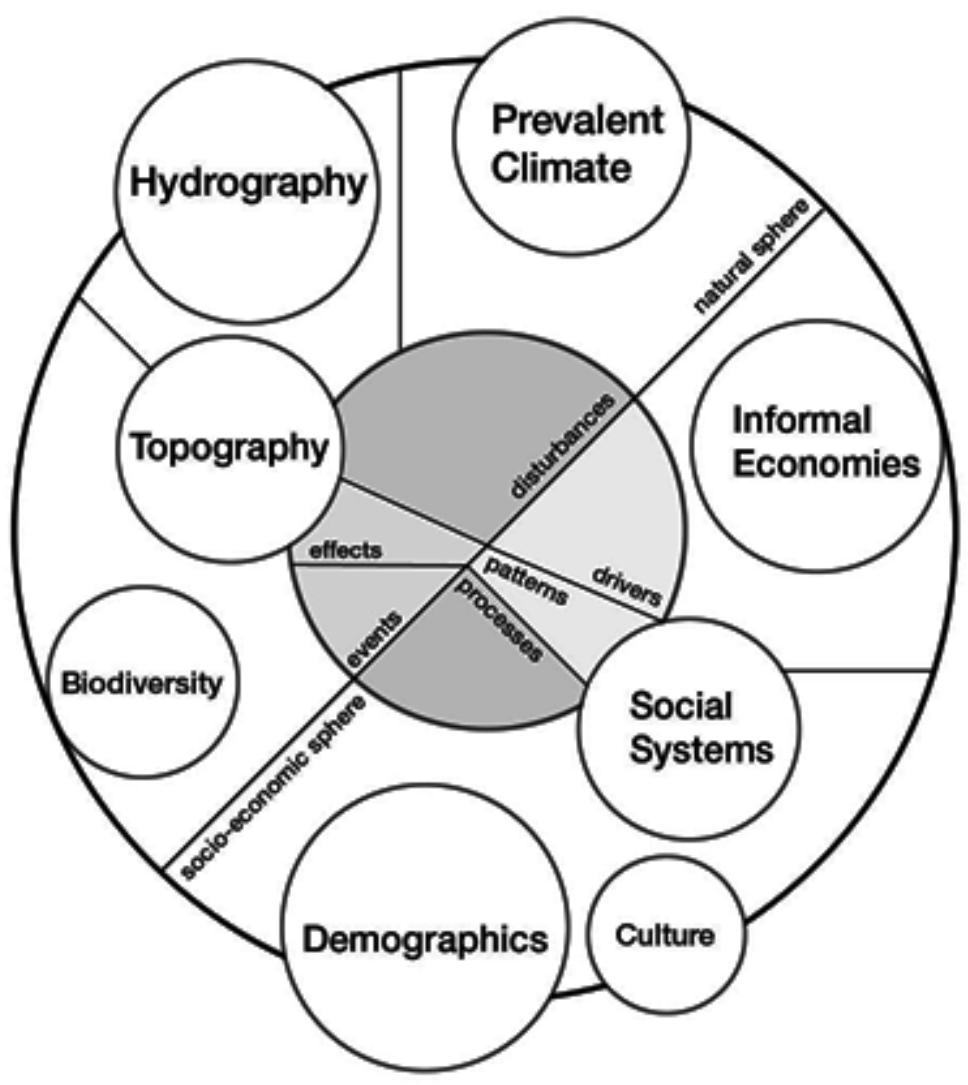

Figure 4. Components and processes of change identified through the adaptation of established frameworks and principles for studying urban ecosystems for the case study of Caracas. Own elaboration.

Data collected on informal settlements allowed for the identification of components and processes of change in the case study area. It also led to an initial categorization grounded on the theoretical framework for studying urban systems. The categorization described specific climates in slums, urban vegetation, hydrography, soil, events, social systems, including demographic aspects, economies, and culture. Specifically, established frameworks analyzed in the literature led to four main features of systems ecology to be applied to informal settlements in resembling processes and dynamics characteristic to their complex ecosystems.

\subsection{Scaling informal settlements}

"To represent Caracas requires a method of collage that rearranges the spatial narrative and makes dominant the ordinary stories of city life" (Caracas Urban Think Tank et al., 2005, p. 21).The consideration of scales was previously regarded as useful in recognizing specific features in urban regions, offering opportunities for generalization when typical areas are identified (Endlicher et al., 2007). Here it is argued that multiple prototypes can be found in- formal areas and different mosaics can be created. For scaling the informal, a first national level was considered. This level can be defined by the impacts of socio-political events in the rapid socio-spatial transformation seen in the last decades. The study of the macro-scale of the city considers a generalized view of the informal landscape. At this level, informal settlements display three robust features: (1) their presence, (2) their systematic character, and (3) their permanence. Barrios in Caracas developed rapidly and in a systematic way. Today they appear as a large urban manifestation. Their increasing visual presence is a symbol of a phenomenon that is worthy of acknowledgment.

The mesoscale is characterized by connections, cooperation, and extension patterns. The replication of households and the social organization for construction works are signs of collective capacity. Spontaneity, equal sizes, the same materials, and uniformity in morphology, make this seemingly democratic housing development (Caracas Urban Think Tank et al., 2005) a common feature in many communities. Although these settlements also show a high capacity of pattern replication in different environmental contexts, other networks discovered at the district level represented vulnerabilities. One of the experts interviewed revealed that some hierarchical structures go beyond communal leadership and regular forms of social organizations. Informal 'industries' such as weapon and drug 
trafficking have established unusual 'security' systems that clearly set boundaries between 'districts' or communities, therefore, influencing social and material exchanges.

At the microscale, community organization and resilient capacities have been seen with the occurrence of certain events. Community organization and collective efforts for immediate access to services, and recollection and re-use of materials have been appreciated in the spatial production modes for all localities analyzed. These communities adapt to the immediate environment they have sought to 'colonize'. Natural features and environmental conditions are not only primary shapers of the type of development but constant factors of intermittent instability for the system.

\subsection{Analysis of components and processes in informal systems}

The study of urban ecosystems concerns spatial features and processes in space in time. The spatial features analyzed for the urban informal landscape of Caracas included: prevalent climate, topography, hydrography, and vegetation. The processes in space and time were identified as the development of slums, land use or land occupation, and weather events. The composition of an ecological context was done by identifying as many socio-natural elements as possible. Based on the human ecosystem framework and the integrated model of humans and ecological processes, some system components and some processes were adapted to the informal context. Lack of functional capacities or access to technical and systematic data challenged the inventory of components. Many of these components and processes have been identified according to their relevance in the sense-making of this adaptation framework, and with the aim of showing their current state and imagined the position in the ecosystem. Specific identification and extended description of all the identified components is beyond this research and further exploration is highly advised for better assessment of informal processes.

\subsubsection{Demographics}

The production capacity in the barrio development has been reviewed as surpassing the speed of external responses to housing demands. The combination of incremental techniques, lack of regulatory standards, and lack of formal organization are manifested in a prevailing self-construction capacity. However, this capacity is alarmingly questioned by the lack of risk assessment, lack of institutional support, and planning perspectives. In the imagined system, the latter would represent backing functions. According to one academic expert, informal development and consolidation are subjected to stages, these stages depend on levels of social cohesion, access to resources, local natural processes, external influencing forces, and local knowledge of the area. This means that by building their own spaces, informal dwellers also learn about the diverse dynamics of the place, use their individual skills in construction works, drainage and sewage works, and design for their own benefit. Main features to be acknowledged in the development process are local knowledge, local agency, and drive.

An imagination of the dynamic system of barrio development in terms of spatial production illustrates how drivers such as housing demands, population growth, or urban migration, benefit from patterns of self- construction capacity or social organization and go on to a reproduction process. The speed with which these processes take place can be highly influenced by other external factors such as availability of resources, natural events, or governmental interventions. These external factors are considered disturbances to the cycle (Fig. 5). 


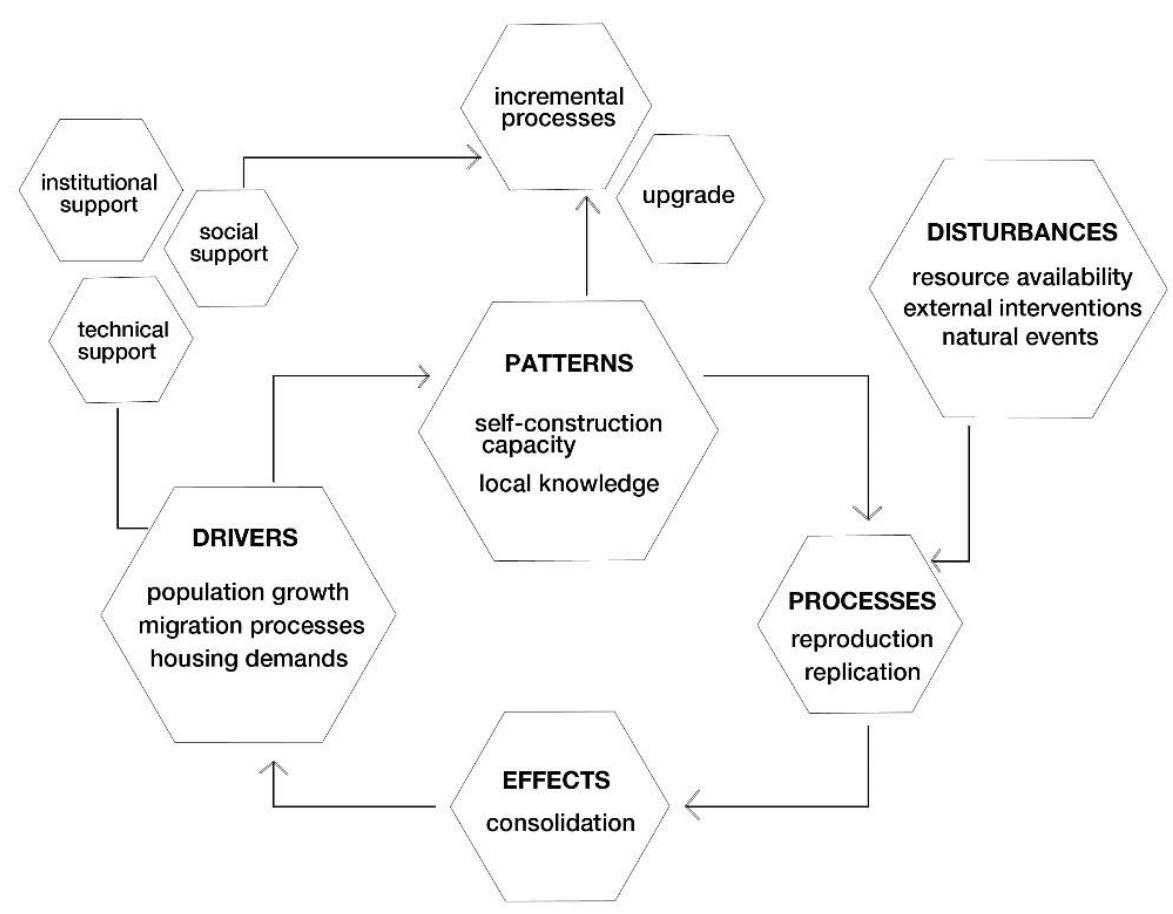

Figure 5. The cycle of barrio development cycle composed of drivers, patterns, processes and external influential factors or disturbances. Own elaboration.

\subsubsection{Climates}

For the analysis of urban climates, one of the main starting points were the records of intense increase in temperature in Caracas. Among different causes, construction materials were considered drivers for the temperature increase. The availability of formal measuring instruments and techniques in the city, and the conventional planning and design mitigation strategies advocated by several institutions are considered passive components that give support to the system. However, structural barriers shift the attention towards a re-evaluation of the interactions between climate and spatial production, and vice versa. Space between buildings in areas where space is scarce and no regulations are given results impossible. Enhancing or replacing construction materials at a large scale is linked with the issue of access to resources and technical knowledge. The overestimation and the increasing pressures on the Avila Mountain contribute to temperature events. The refresher character of the mountain, as well as the advantages of circulatory patterns of the valley of Caracas, need to be strategically reassessed. Opportunity is seen in landscaping projects and green corridors that consider the relatively soft tissue of slum areas. 


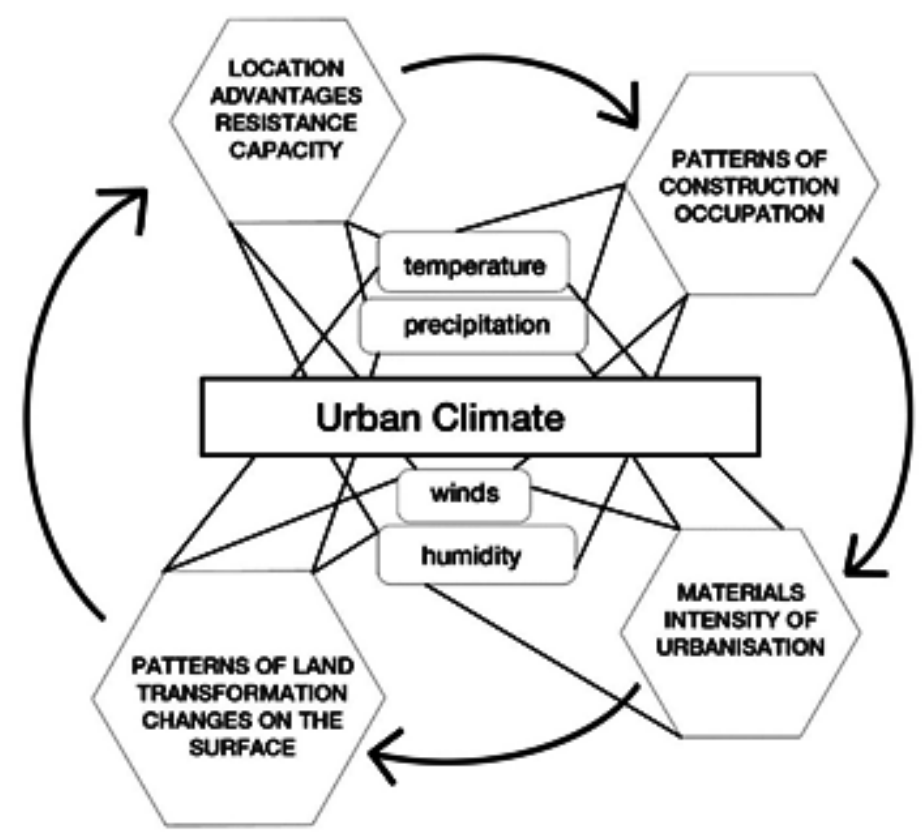

Figure 6. Representation of relationships and influences of different processes of change on urban climates within informal settlements. Own elaboration.

\subsubsection{Hydrography and Topography}

As determining elements influencing settlement allocation, hydrography and topography are considered assets for the city. However, informal development has contributed to the degradation of natural water networks, and topographic instability represents a constant threat for weak structures found in slums. The interactions between slums and these two natural aspects are understood as reciprocal and inversely proportional, meaning that increasing pressure on either of those will increasingly reduce their capacity. Bodies of water continuously exposed to uncontrolled pollution will increasingly degrade in composition, while intensified pressure on soil from clearance and fillings, will continue after its resistance, eventually resulting in landslides and slope failures.

A distinctive type of development within the informal landscape of Caracas is the Quebrada ${ }^{3}$ settlement. This form of occupation found commonly in topographic depression as interstices respond to the prominence of bodies of water in the city within the natural water network, and the easy access to ecosystem services such as transporting functions, and provision of fresh water. However, Quebrada is exploited by informal urbanization, and their natural functions are replaced by sewage functions and refuse disposal. Furthermore, the advantage of easy access to free, uncontrolled refusal points is contrasted with smells, an overall unsanitary environment, and hazardous living conditions. Processes of informal urbanization along rivers and ravines produce stress on soil stability, which elevates the level of risks. Moreover, the lack regulations controlling hazardous development make slum dwellers the main victims in the event of flooding and landslides. The suggested assessment of this sub-system includes an analysis of the features and behaviors, disturbances and effects, of specific patch areas.

\footnotetext{
${ }^{3}$ Quebrada: ravine or small body of water deriving from a river
} 


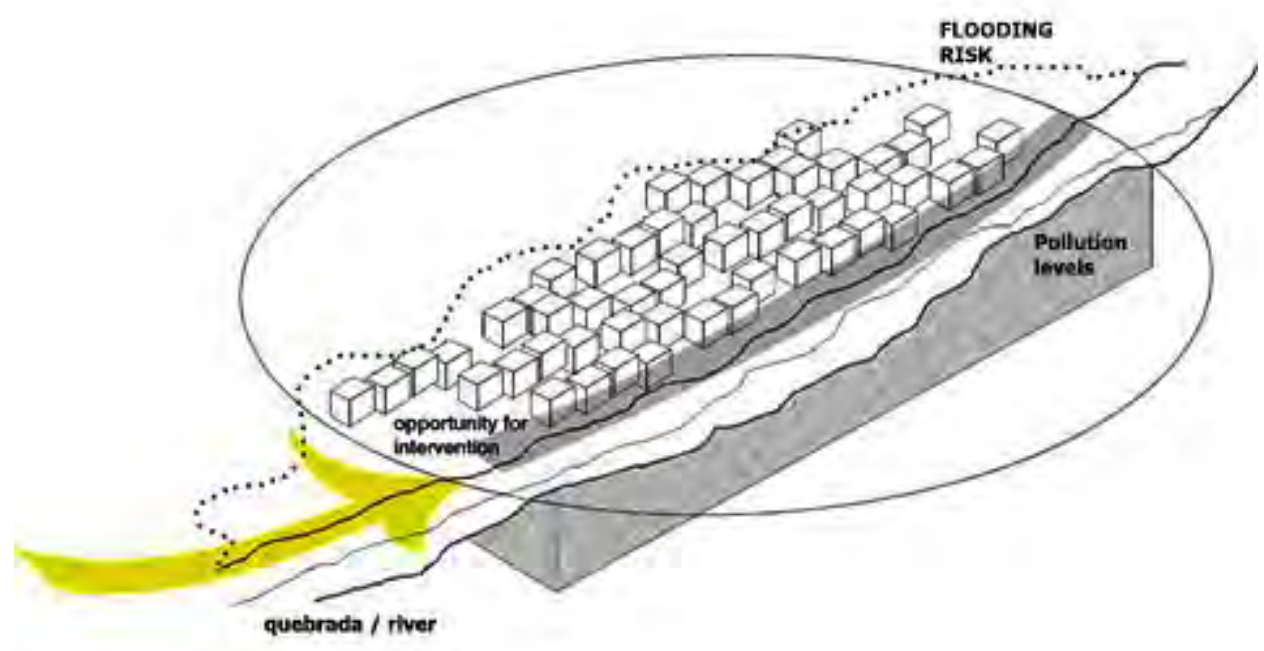

Figure 7. An alternative assessment to Quebrada settlements. The particularity may be pollution levels, the disturbance can be the flooding risk, and the emerging phenomena or change can be represented by local scale interventions that considered all the above. Own elaboration

\subsubsection{Biodiversity}

Biodiversity is not often a central target in upgrading projects and is limited to small interventions. However, increasing consideration of the advantages of integrating this aspect in upgrading projects has opened a window for a new understanding of biological aspects and their role in social development. Although natural function has been neglected by urbanisation processes and debilitated by irregular natural events, an opportunity is seen in added functions aiming at protecting natural species, developing soil for productive activities or urban agriculture, enhancing the structure of the soil as a retainer, and encouraging the increase in vegetation and their cleansing and filtering advantages. Potential new links to microeconomies are also seen as enhancements in the evolution of the system.

\subsubsection{Social systems}

Within the social systems, the analysis identified social hierarchies, informal exchange, security systems, and community organization. The different hierarchies may be manifested in generational bonds or community ties to the place, actors in the role of community leaders, and groups involved in conflictive crime related affairs. Community organization is represented in many ways. It may be powered by external influences such as NGOs or experts who have passed information and built capacities in certain communities, by institutional empowering tools as in the case of the Misiones Bolivarianas ${ }^{4}$ and Consejos Comunales ${ }^{5}$ implemented by President Hugo Chávez. Alternatively, as reported in the interviews, community organization may emerge from essential familiar bonds or cultural ties. In many cases, organization comes from ideas for informal projects and collective efforts in pro of the community during gatherings and celebrations.

Another aspect relates to the informal exchanges occurring in slums. One of the interviewees gave an account of the links existing between informal social systems and economic development. Knowing the structural difficulties in accessing formal jobs, slums dwellers create employment based on supplying direct services to the immediate network of household in the community. Some of these services include improvised day-cares, kiosks, and food stalls. These activities can become so rooted among the community and built such strong links that often influence relocation decisions. These social networks whether rooted or transferable become then, decisive variables in slum systems. Informal exchange and informal economies are also an aspect that deserves a change in focus when analyzed from the external perspective of the formal city.

\footnotetext{
${ }^{4}$ Misiones: Social assistance plans developed and designed during Hugo Chavez's administration in 2003 with the objective of ending extreme poverty through edu- cational programmes, alphabetization, free medical care, and subsidized credits for housing purchase.

${ }^{5}$ Consejos Comunales: Advanced form of organization given to residents of a de- termined community who must assume the practice of popular power, and imple- ment the decisions taken by the community.
} 


\subsection{Assessing disturbances in the behavior of the system}

Grounded on the properties of systems analyzed in the theoretical framework, a distinctive aspect in the resilient behavior of slum ecosystems defined by the interactions and responses from informal dwellers to disturbances manifested in natural events and social instabilities. Reactions from slum dwellers to events of any nature, and especially to natural disasters were classified depending on three variables. The first variable is the intensity of the event, intensity and recurrence of natural events are highly unpredictable. The second variable is the resistance capacity, and the third, the adaptive capacity to new conditions. While the first variable can only be identified and measured after the event, the second and third variables can be measured and developed. In the case of flooding, for example, interviews revealed that proposals on water management systems for slum areas significantly considerate slope-friendly designs in the configuration of channels and other water structures. The development of resilient behaviors should understand and regard natural cycles instead of fighting or blocking them.

Informal hierarchies in social systems generally manifested in criminal activities are also considered social disturbances. The influences of crime on regular processes of development, external interventions, and local exchanges of social or material nature, are considered constant agents of instability for social systems. Crime is a delicate social issue and one of the biggest problems of Caracas. Three of the interviewees warned the impossibility to access some areas without having to deal with gang leaders and a number of subordinates who control and establish a sort of security system. Beyond the structural problems linked to lack of education and poverty, crime is appreciated as a variable that limits the exchange of resources of any nature, of information and social relations. Changes in the system, when this disturbance is minimized, can be appreciated in current efforts aiming at public space production and local economic development, yet, the mobility and extent of this disturbance in time-based on their cultural impact in generations, remains to be seen.

\subsection{Re-positioning the informal in the city landscape}

Interpretation of the function of cities, as reviewed in Harris \& Ullman (1945), organized cities in three categories: cities as central places, cities with specialized functions and transport cities. The reinvention of Caracas' landscape (Fig. 8) after the integration of the informal as functional entities with specific patterns and behaviors allows for informal processes to intersect macro-scale functions in the city, as they already do but informally. This change of perspective may recognize many areas of the informal city as central places, areas with special functions, and even transporting or exchanging spaces through internal or external networks; changing the entire urban-support dynamic of the city.

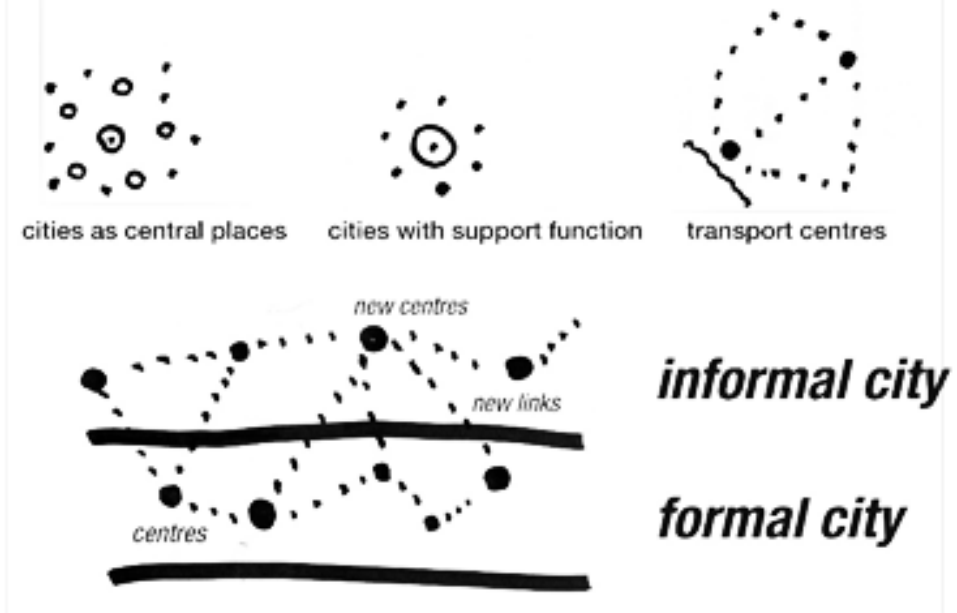

Figure 8. Re-imagined Landscape of Caracas. Representation of new functions and interactions based on the principles of Harris \& Ullman (1945) of the functions of cities. Own elaboration.

\subsubsection{The slum ecosystem}

The aim of this paper is to elaborate an analytic framework based on grounded models and understandings of systems that could adapt to the context of slums, challenging conventional aiding or mitigating approaches and linking them to their ecology to further their potentials. During the research process, new ideas and interpretations of the original frameworks contributed to the illustration of the complex structures and functions of informal areas, and reciprocal relationships were significant features discovered in the analysis. 
The slum ecosystem analysis may be initiated with the identification and of components, patterns, and interactions found in informal areas at specific scales. The prototypes may vary due to different processes or patterns discovered at the different scales. Multiple inventories of variables and relationships can generate a template to appreciate the system's interactions. The study of different levels of complexities will allow the development of the system's history, and its consistent analysis will enable forms of identifying and positioning components.

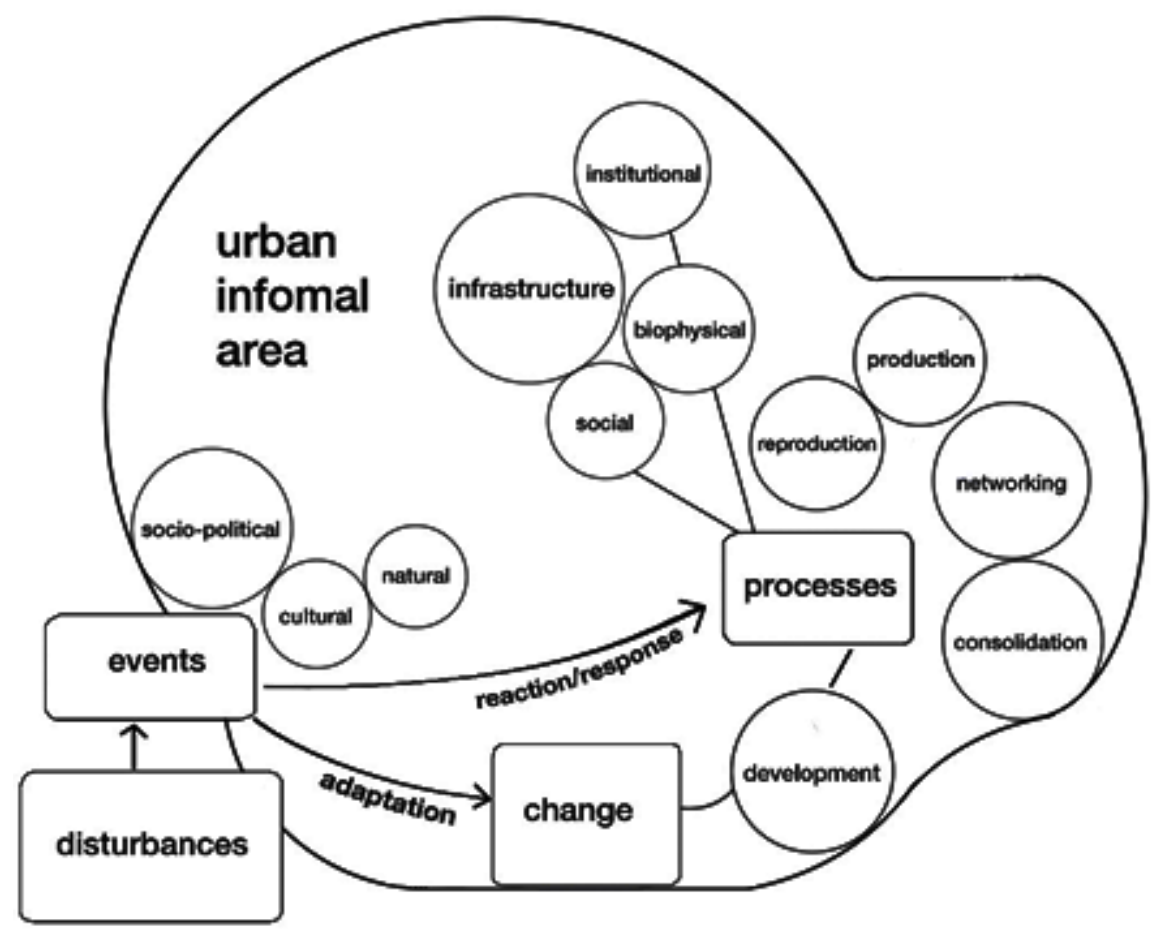

Figure 9. The slum ecosystem as interpreted for the Caracas case. Variables are identified and related to processes of change. Own elaboration.

\section{Policy implications and limitations of the study}

This analysis suggests that there are reasons to rethink systems ecology as an entry mechanism for the urban informal in the city and the general ecological scrutiny. Considering the urban as a set of complex socio-environmental transformations (Heynen et al., 2006) and urban ecology as the discipline to thoroughly study these transformations (Pickett et al., 2001), the consolidated features found in slums enable them to take part in a socio-environmental discourse that can comprehensively be analysed through the ecological lens.

Pickett et al. (2011) point to the need for an understanding of the ecological manner in which cities work, as such information is key for decision-makers in planning and conservation. They argue that it is essential for the study of urban systems to include less densely occupied areas so as to take in a broad range of urban effects and determine possible thresholds of change across space comprising not only city cores, but suburban areas, and connected villages. This study recognizes the inclusion of connected urban areas with a special focus on extensively occupied spaces adjacent to the city core, in this case, dominated by informal urbanization. Furthermore, in response to the lack of attention given to the aspects of social life that focus on institutional efforts to educate about the impacts of built environments on nature at localised levels (Wali et al., 2003), this analysis stresses on an initial focus on the internal social dynamics and local knowledge in informal settlements at the community level, regarding external agents as catalysers or supporting features with measurable influence.

The "re-entry" of the ecological perspective into urban theory is essential to both understanding the urban and engaging in significant environmental politics (Heynen et al., 2006, p. 3). It is also understood that the differential processes by which societal variables such as economic and political conditions, and ecological variables both in the natural and built environment are integrated, concern urban policy (Wali et al., 2003). The complex internal and external politics encircling the topic of slums in Caracas represent a significant barrier to the inclusion of integrative development processes. Public and private indisposition, lack of knowledge, internal power dynamics, frustration is driven by poverty, and even fear, in many cases, obstruct any form of access to informal areas. As indicated by Endlicher et al. (2007), any improvement in the quality of life in cities requires individual and collective efforts, the same efforts required for making urban areas more sustainable. A common ground where urban ecology is linked to 
urban policy. In Venezuela, and specifically in Caracas, the collapsing socio-political and economic situation continues to hinder any opportunity for new configurations in political ecology and their policy implications.

Another issue concerns availability and accessibility of data for analyzing informal areas. The data-based nature of ecological frameworks analyzed for the study hinted at the need to establish even prior stages for identifying as many components as possible before analyzing their processes of change and interactions with other components for areas where data is unavailable or has not been collected. However, for the course of the research, variables which were not able to be identified due to missing data allowed for other variables to emerge in the modification and adaptation of ecological models from the literature. In these cases, some inputs received different interpretation for their integration in the system. Therefore, the need for a socio-ecological memory that will allow for the registry and exploration of the development of the ecosystems. Furthermore, the flexibility offered by the integrative model of Alberti et al. (2003), is seen as useful in their ability to contextualize and allow for the identification of different drivers, processes, effects, and patterns in informal areas. The same adaptability is seen in the idea of considering events and disturbances as inputs that can enhance the adaptive capacity and the already resilient behaviors found in slums. The inventory of components is seen as central in bringing together analytic frameworks and implementation strategies.

\section{Conclusions}

This paper was intended as an initial contribution to a new functional consideration of urban informal settlements that aims at inclusive cities capable of recognizing and unfolding the already existing informal relationships occurring within. The applicability of integrating systems ecology to informal development is seen in the possibility of reinventing ways in which the informal can integrate to the totality of the city. The systems thinking involved in representing processes and cycles found in slums shows potential in displaying relationships with external components and processes taking place in the city. This approach considers the social, spatial, and environmental dimensions that take part in the process of urbanization, and allows for the adaptation of frameworks rooted in the field of urban ecology to set initial layouts for identifying processes and components of urban informal ecosystems. In this case, the utilisation of a systems approach and the adaptation of ecological frameworks led to an inventory of components and processes in informal areas, the rendering of different slum cycles that allow for re-assessment and modifications in the case of disasters, disturbances or interruption of projects, and a first approximation to the informal ecosystem in the city of Caracas.

Aiming at inclusiveness for established and new spreading areas, the study of these relationships can lead to the identification of needs and strategies to improve evolving urban systems; needs that might suggest re-organisation, insertion of new components or development of new relationships, and strategies that might involve different levels of participation from internal and external stakeholders, different inputs for policy design and implementation, or adjustment of behaviour. Reinventing Caracas or re-drawing the city may imply that informal processes and interventions can change macro-scale external functions (as they already do in informal ways). The informal can turn into an important part of city expansion when understood as an intrinsic part of the totality that is the city. Informal Ecology explores how pressures of environmental change, natural disasters and socio-cultural deviations affect the informal landscape of the city and can similarly be tackled by envisioning frameworks capable to adapt to their uncertain conditions. Informality as a transformative mode of urbanization entails a different dynamic which allows for a re-imagination of formal-informal components interacting in a broader system. This big picture allows for the capacities found in slums to be integrated into the process of expansion and development of the city. However, that big picture can only be achieved if the identification, acknowledgment, and appraisal of the informal occurs. In other words, it is difficult to envision better urban futures without understanding how the dissimilar parts of the city work. As innovation in planning advances on data-driven models for smart development, there is a need to create, adapt, and assemble compelling models that can also apply to informal development, where systems and data have a different rigor. Informal development not only needs spatial considerations but structural support.

\section{Acknowledgments}

This manuscript is based on the results of a previous investigation for an unpublished Master Thesis submitted and accepted by the Department of Urban Development for the completion of the degree of Master of Science in Urban Development at the Technische Universität Berlin - Campus El Gouna. All the data collected as well as the reflections of findings and results are of my intellectual property. I would like to expressively thank Prof. Undine Giseke (TU Berlin) and Prof. Maarten Siebel (UNESCO-IHE) for their guidance and substantive direction.

\section{References}

1. Abel, T. (1998). Complex adaptive systems, evolutionism, and ecology within anthropology: interdisciplinary research for understanding cultural and ecological dynamics. Journal of Ecological Anthropology, 2(1), 6-29. Retrieved from http://scholarcommons.usf.edu/cgi/viewcontent.cgi?article $=1101 \&$ context $=$ jea 
2. Alberti, M. (2005). The Effects of Urban Patterns on Ecosystem Function.

3. International Regional Science Review, 28(2), 168-192. https://doi.org/10.1177/0160017605275160

4. Alberti, M., Marzluff, J. M., Shulenberger, E., Bradley, G., Ryan, C., \& Zumbrunnen, C. (2003). Integrating humans into ecology: opportunities and challenges for studying urban ecosystems. BioScience, 53(12), 1169-1179. Retrieved from http://bioscience.oxfordjournals.org/content/53/12/1169.short

5. Ayala, A. (2009). Community Organisations, Misiones and Integration of Barrios of Caracas, Venezuela-The Case of the CAMEBA Upgrading Project. IHS Working Papers. Institute for Housing and Urban Development Studies (IHS), (21). Retrieved from http://hdl.handle.net/1765/32182

6. Bolívar, T., \& Baldó, J. (Eds.). (1996). La Cuestión de Los Barrios: Homenaje a Paul-Henry Chombart de Lauwe (1a ed). Caracas, Venezuela: Monte Avila Editores Latinoamericana : Fundación Polar: Univer- sided Central de Venezuela.

7. Caracas Urban Think Tank, Brillembourg Tamayo, A., Feireiss, K., Klump- ner, H., \& Kulturstiftung des Bundes (Eds.). (2005). Informal city: Caracas case. Munich; New York: Prestel.

8. Caselli, I. (2013, July 5). Fighting crime in Petare, Venezuela's toughest slum. Retrieved 11 August 2015, from http://www.bbc.com/news/worldlatin-america-23181510

9. Cilento, A. (2012). Políticas de alojamiento en Venezuela: aciertos, errors y propuestas. Tecnología Y Construcción, 24(2), 35-58. Retrieved from http://190.169.94.12/ojs/index.php/rev_tc/article/view/261

10. Collins, J. P., Kinzig, A., Grimm, N. B., Fagan, W. F., Hope, D., Wu, J., \& Borer, E. T. (2000). A New Urban Ecology Modeling human communities as integral parts of ecosystems poses special problems for the development and testing of ecological theory. American Scientist, 88(5), 416-425. Retrieved from https://www.americanscien- tist.org/issues/id.777,y.2000,no.5,page.1/postComment.aspx

11. Córdova Sáez, K. (2009). Spatial Geotechnology applied to Urban Climate studies: thermal analysis of urban surface and urban land use in Caracas city (Fifth Urban Research Symposium 2009) (p. 14). Institute of Geography and Regional Development, Area of Energy and Environment, Central University of Venezuela.

12. Córdova Sáez, K. (2011). Impacts de las islas térmicas o islas de calor ur- bano, en el ambiente y la salud humana. Análisis estacional comparativo: Caracas, octubre-2009, marzo-2010. Terra Nueva Etapa, 27(42), 95-122. Retrieved from http://www.redalyc.org/articulo.oa?id=72121706005

13. Córdova Sáez, K., \& Singer, F. (2010, March 15). Zonas de Caracas presentan diferentes temperaturas [Noticias24.com]. Retrieved from http://www.noticias24.com/actualidad/noticia/147659/regis- tros-de-temperatura-revelo-que-caracas-son-dos-ciudades/

14. De Lisio, A. (2001). La evolución urbana de Caracas. Indicadores e inter- pretaciones sobre el desarrollo de la interrelación ciudad-naturaleza. Revista Geográfica Venezolana, 42(2), 203-226. Retrieved from http://www.saber.ula.ve/handle/123456789/24514

15. Dearing, J. A., Bullock, S., Costanza, R., Dawson, T. P., Edwards, M. E., Poppy, G. M., \& Smith, G. M. (2012). Navigating the Perfect Storm: Research Strategies for Social-ecological Systems in a Rapidly Evolving World. Environmental Management, 49(4), 767-775. https://doi.org/10.1007/s00267-012-9833-6

16. Dengo, G. (1953). Geology of the Caracas region, Venezuela. Geological Society of America Bulletin, 64(1), 7-40. Retrieved from http://gsabulletin.gsapubs.org/content/64/1/7.short

17. Diaz, V. J. (1992). Landslides in the squatter settlements of Caracas; towards a better understanding of causative factors. Environment and Urbanization, 4(2), 80-89. https://doi.org/10.1177/095624789200400208

18. Dooley, L. M. (2002). Case study research and theory building. Advances in Developing Human Resources, 4(3), 335-354. Retrieved from http://adh.sagepub.com/content/4/3/335.short

19. Dubois, A., \& Gadde, L.-E. (2002). Systematic combining: an abductive approach to case research. Journal of Business Research, 55(7), 553560. Retrieved from http://www.sciencedirect.com/science/arti- cle/pii/S0148296300001958

20. Dubois, A., \& Gadde, L.-E. (2014). 'Systematic combining'-A decade later. Journal of Business Research, 67(6), 1277-1284. https://doi.org/10.1016/j.jbusres.2013.03.036

21. Endlicher, W., Langner, M., Hesse, M., Mieg, H. A., Kowarik, I., Hostert, P., ... et. al. (2007). Urban Ecology-Definitions and Concepts. Shrinking Cities: Effects on Urban Ecology and Challenges on Urban Development, 1-13. Retrieved from http://www.peterlang.com/exportdatas/exportfiles/onix/intro/9783631566107_lese- probe01.pdf

22. Fath, B. D., Dean, C. A., \& Katzmair, H. (2015). Navigating the adaptive cycle: an approach to managing the resilience of social systems. Ecology and Society, 20(2). https://doi.org/10.5751/ES-07467-200224

23. Garland, A. M., Massoumi, M., \& Ruble, B. A. (2007). Global urban poverty: setting the agenda. Washington, D.C.: Woodrow Wilson International Center for Scholars. Retrieved from https://www.wil- soncenter.org/sites/default/files/GlobalPoverty.pdf

24. Harris, C. D., \& Ullman, E. L. (1945). The Nature of Cities. The ANNALS of the American Academy of Political and Social Science, 242(1), 7-17. https://doi.org/10.1177/000271624524200103

25. Harrison-Conwill, G. (2011). The Race toward Caraqueno Citizenship: Negotiating Race, Class, and Participatory Democracy. The ANNALS of the American Academy of Political and Social Science, 637(1), 165-183. https://doi.org/10.1177/000271621140802

26. Hernández, F., Kellet, P., \& Allen, L. K. (Eds.). (2012). Rethinking the Informal City. Critical Perspectives from Latin America (Vol. 11). New York - Oxford: Berghahn Books.

27. Heynen, N., Kaika, M., \& Swyngedouw, E. (Eds.). (2006). In the nature of cities: urban political ecology and the politics of urban metabolism. London; New York: Routledge. Retrieved from http://sam- ples.sainsburysebooks.co.uk/9781134206476_sample_900467.pdf

28. McGuirk, J. (2014). Radical Cities. London; New York: Verso.

29. McHale, M. R., Bunn, D. N., Pickett, S. T., \& Twine, W. (2013). Urban ecology in a developing world: why advanced socioecological theory needs Africa. Frontiers in Ecology and the Environment,11(10), 556-564. https://doi.org/10.1890/120157

30. McIntyre, N. E., Knowles-Yánez, K., \& Hope, D. (2000). Urban ecology as an interdisciplinary field: differences in the use of 'urban' between the social and natural sciences. Urban Ecosystems, 4(1), 5-24. Retrieved from http://link.springer.com/arti- cle/10.1023/A:1009540018553

31. Melosi, M. V. (2010). Humans, Cities, and Nature: How Do Cities Fit in the Material World? Journal of Urban History, 36(1), 3-21. https://doi.org/10.1177/0096144209349876

32. Parthasarathy, D. (2009). Rethinking Urban Informality: Global Flows and the Time-Spaces of Religion and Politics. International Conference on 'Urban Aspirations in Global Cities', Max Planck Institute for the Study of Religious and Ethnic Diversity, Gottingen, Germany,9-12. Retrieved from http://www.mmg.mpg.de/fileadmin/user_up- load/pdf/gcc/Parthasarathy.pdf 
33. Pickett, S. T. A., Cadenasso, M. L., Grove, J. M., Boone, C. G., Groffman, P. M., Irwin, E., ... Warren, P. (2011). Urban ecological systems: Scientific foundations and a decade of progress. Journal of Environmental Management, 92(3), 331-362. https://doi.org/10.1016/j.jenvman.2010.08.022

34. Pickett, S. T. A., Cadenasso, M. L., Grove, J. M., Nilon, C. H., Pouyat, R.

35. V., Zipperer, W. C., \& Costanza, R. (2001). Urban Ecological Systems: Linking Terrestrial Ecological, Physical, and Socioeconomic Components of Metropolitan Areas. In J. M. Marzluff, E. Shulen- berger, W. Endlicher, M. Alberti, G. Bradley, C. Ryan, ... C. ZumBrunnen (Eds.), Urban Ecology (pp. 127-157). Springer US. Retrieved from http://link.springer.com/chapter/10.1007/978-0-387-73412-5_

36. Porter, L., Lombard, M., Huxley, M., Ingin, A. K., Islam, T., Briggs, J., ... Watson, V. (2011). Informality, the Commons and the Paradoxes of Planning: Concepts and Debates for Informality and Planning Self-Made Cities: Ordinary Informality? The Reordering of a Rom- any Neighbourhood The Land Formalisation Process and the Peri-Urban Zone of Dar es Salaam, Tanzania Street Vendors and Planning in Indonesian Cities Informal Urbanism in the USA: New Challenges for Theory and Practice Engaging with Citizenship and Urban Struggle Through an Informality Lens. Planning Theory \& Practice, 12(1), 115-153. https://doi.org/10.1080/14649357.2011.545626

37. Ritchie, J., \& Lewis, J. (Eds.). (2003). Qualitative research practice: a guide for social science students and researchers. London; Thousand Oaks, Calif: Sage Publications.

38. Roy, A. (2005). Urban Informality: Toward an Epistemology of Planning.

39. Journal of the American Planning Association, 71(2), 147-158. Retrieved from http://urbanpolicy.net/wp-content/uploads/2012/11/Roy_2005_JAPA_UrbanInformality_Epistemology OfPlanning.pdf

40. Roy, A. (2011). Slumdog Cities: Rethinking Subaltern Urbanism. International Journal of Urban and Regional Research, 35(2), 223-238. https://doi.org/10.1111/j.1468-2427.2011.01051.x

41. Sertich, A. N. (2010, May 17). República Bolivariana de Venezuela. Retrieved from https://favelissues.com/2010/05/17/republica-bolivari- anade-Venezuela/

42. United Nations. (2016, April). United Nations Resources for Speakers on Global Issues. $\quad$ Retrieved $4 \quad$ March 2016 , from http://www.un.org/en/globalissues/briefingpapers/cities/vital- stats.shtml

43. United Nations Human Settlements Programme. (2016). Explore urban open data. Retrieved from http://urbandata.unhabitat.org/exploredata/?coun- tries=VE\&regions=489\&indicators=slum_proportion_living_urba n,urban_population_cities, hiv_prevalence_15_to_49_year

44. Wali, A., Darlow, G., Fialkowski, C., Tudor, M., Del Campo, H., \& Stotz, D. (2003). New methodologies for interdisciplinary research and action in an urban ecosystem in Chicago. Conservation Ecology, 7(3), from http://www.nrs.fs.fed.us/pubs/jrnl/2003/nc_2003_wali_001.pdf

45. Wright, G. (2005). Informal Cities, Multiple Realities. In the Informal city: Ca- racas case (p. 368). Munich; New York: Prestel

46. Yin, R. K. (1994). Case Study Research. Design and Methods (2nd ed). Thousand Oaks: Sage Publications.

\section{Unpublished Master Thesis}

1. Quintero, N. (2016). Slum Ecologies, Rethinking the urban informal landscapes of Caracas (Unpublished Master thesis). Technical University of Berlin Campus El-Gouna, Berlin, Germany. 